\title{
Tangram Proficiency Leading to Numeracy Skills Enhancement
}

\author{
Elymar A. Pascual \\ elymarpascual@rocketmail.com \\ Department of Education, Nagcarlan District, Nagcarlan, Laguna, Philippines, 4002
}

\begin{abstract}
This study focused on determining the ways in which numeracy skills are enhanced through tangram. An exploration on ways of solving patterns in tangram, power of imagination, enhancement of logical, analytical and critical thinking, and desirable characteristics being formed in playing tangram became part of this study. The community quarantine in the Philippines due to COVID-19 caused the design of this study to gather data through online tangram tournament. Seven learners accepted the seven-day challenge. They solved 55 tangram puzzles and answered 6 qualitative questions. After a week of tangram challenge, the following findings were established. In solving tangram puzzles, players can consider (1) looking into the details, (2) trial-and-error, or (3) planning. The best ways to solve tangram puzzles are (1) focusing on the whole portion, (2) focusing on the bigger portions, or (3) focusing on the smaller portions. Imagination plays an important role because (1) it makes things clear and the solution easier to obtain, (2) it put things into proper perspective, and (3) it reduces useless effort. Logical, analytical and critical thinking are enhanced because (1) proper flow of thought in the process of making decisions or conclusion is exercised, (b) deep thinking in considering different ways and solutions is given importance, and (c) correct reasoning based from facts or evidence is practiced. Numeracy skills are enhanced due to the following reasons: (1) Tangram can train the mind in dealing with abstracts and apply them in concrete things, (2) Tangram can assist in molding right attitude towards achieving goals and success, thereby improving skills like numeracy, (3) Tangram can aid learners in looking at the big picture without taking for granted the small details, and (4) Tangram can enhance skill in solving word problems. Desirable characteristics were discovered byproducts of playing tangram.
\end{abstract}

Keywords: Numeracy; Skill; Tangram

\section{Introduction}

Tangram, which is literally "seven pieces of boards", was considered ancient in its origin, as tradition tells us. It has been said that during the Song Dynasty in China, six tables were being put together to assemble different forms, until another triangle was added and since then on, the seven-piece board was being played using different materials like wood, metal, concrete, plastic, cardboard, or other indigenous materials.

But on the recorded history, it was made known to the western word on the outset of the nineteenth century. American and Chinese ships brought the concept to America. In the year 1802, an American crew gave the pieces to his son, making the tangram known to the western world. Since then, three prominent figures were known to have acquired or popularized it. Lewis Carroll who is an author and a mathematician was known to have a Chinese book of tangrams and was playing it. Napoleon Bonaparte, while being imprisoned in St. Helena, was known to play tangrams, probably to exercise his mind and to take some boredom. Thomas Hill who became the President of Harvard University published a book entitled Geometrical Puzzle for the Youth last 1848. This book was known to contain tangram puzzles and was the 
first to popularize the concept outside China. (Wikipedia)

Philippines is not the least in playing tangrams. Since there are many Chinese schools here in the Philippines which caters quality education not only to Chinese migrants but also to Filipinos, tangrams were brought as part of Mathematics, particularly Geometry. Several studies were already done on the aspect of assistance of tangram in understanding Geometry concepts. But none so far have looked deep into the power of using tangram in aiding learners towards developing and enhancing numeracy skills. This study would explore on the various assistance of using tangram puzzles towards holistic learners' development that would enable them to face different areas in Mathematics, whether it is Geometry, Algebra, Trigonometry, Calculus and other branch that needs numeracy skills.

Since the year 2003 when the author of this study started his professional teaching career, he has already included the use of tangram and soma cubes in the study of Mathematics. A 5-minute play to elementary and high school learners were being spent before the beginning of the day's session to catch learners' interest, to lighten up the day, and to set the mind in motion. Since then, the author has been fascinated with the magic of tangram in aiding learners' towards developing and enhancing numeracy skills.

The extended Enhanced Community Quarantine (ECQ) in the Philippines from April 13 to April 30 due to COVID-19 reinstated the passion of the author to explore on the power of the use of tangram in aiding learners toward numeracy development and enhancement. This is in consonance with the mandate of the Department of Education in the Philippines, under the New Results-based Performance Management SystemPhilippine Professional Standards for Teachers RPMS-PPST scheme (Department of Education, 2018). The module 4 of the said scheme encourages meaningful exploration for learners, discovery and hands-on activities. The author of this study invited the learners through social media to join in a seven-day challenge of playing tangrams, while at the same time, soliciting survey questions to them with regards to the role of tangram in developing numeracy skills (Appendix A, The Challenge Given). Seven learners from the secondary, tertiary and college graduate levels accepted the challenge. The author and the players agreed on a seven-day schedule of playing tangrams with rewards for those who will have the most number of points. Their participation in the development of the research by answering qualitative questions was given permission (Appendix B, The Do's and Don'ts in Playing Tangram; Respondents Informed Consent). The players were also excited that they would learn 55 patterns during the entire seven-day challenge. They were also to receive certificates of completion in playing tangrams. All of these made the players decide to join the challenge and to be part of the exploration. And so, this study was conceptualized and started.

\section{Review of Related Studies and Literature}

Several studies have been conducted about benefits of playing tangram to understanding important concepts in Geometry and other areas of Mathematics, and this is the role of this part of this paper to look back on the results and findings of those studies that would give light to the present study.

Several known personalities were mentioned by Slocum (n.d.) in this book entitled "Tangram: The World's First Puzzle Craze." The list ranges from scientists to President of United States, from novelist to mathematician, and from general to author. Some people he mentioned were Napoleon Bonaparte, Lewis Carroll, Edgar Allan Poe, Hans Christian Anderson, English scientist Michael Faraday and John Quincy Adams, the sixth President of the United States. This puzzle art is indeed famous because it is being played by all sorts of people.

The study made by Khairiree (2005) had a goal of investigating the effect of playing tangram to the creative thinking skill of the learners. The approach in that study included interaction with the learners while tangram puzzles were being solved. Not only creative thinking skills were developed but also the problem solving skills of the subject-respondents. Learners were able to express their geometric imagination as evident 
in their interaction. They had fund and at the same time have developed positive attitudes towards Mathematics.

Bahadur K.C. (2017) made an experimental study on the effect of playing tangram in geometry class. The two groups, experimental and controlled, were seen to have significant difference in their mean achievement score. The experimental group who played tangram had higher mean than the controlled group. Also, significant improvement was noticed in the experimental group's attendance in classroom, class work completion, habit of doing homework, and style of giving answers. In general, it was concluded that the use of tangram brings positive change to learners.

In his article entitled "Building Students' Mathematical Proficiency: Connecting Mathematical Ideas Using the Tangram," Tchoshanov (n.d.) highlighted tangram as a wonderful way of understanding some competencies in the subjects Number Sense, Algebra, Geometry and Measurement. Through the aid of tangram, the idea of square root and irrational numbers can be unpacked, the reverse relationship between area and side length of a square can be understood, spatial reasoning can be improved, properties of geometric shapes can be easily explained, and measuring area and length can be visualized and computed mentally.

Teaching geometry now have a new dimension through the use of tangram pieces. In the article written by Tian (2012) entitled "The Arts and Mathematics of Tangrams," brief history of tangram was mentioned while series of convex polygons were displayed. The thirteen sample convex polygons that was illustrated his article were all formed using tangram pieces.

The ingenuity of StÖcker-Segre (2015) was displayed when he made use of tangram concepts to discuss about similarity, self-similarity, fractal dimensions and binary numbers. The primary and secondary level arrangement of tangrams can be read in his paper. The total area of the primary and the secondary level tangram arrangement can be used in discussing about the nature of binary numbers from 1 to 16 , which are also the areas of the pieces of tangram, whether singly or when put together. Tchoshanov (n.d.), Tian (2012) and StÖcker-Segre's (2015) writings showed that tangram concepts can be applied not only in Geometry but in other areas of Mathematics as well.

In a suburb elementary school in Tain-Chung City, a study was made to investigate the assistance of tangram in problem solving skills. Lin, Shao and Niramitranon (2011) made use of twenty-five grade 6 learners in this experiment. Their primary findings showed that through using tangram, children's competency in rotation and space of shapes have been improved. Four other significant changes were also noticed among these students: (1) peer negotiation was facilitated, (2) children's optimism towards problem solving was enhanced, (3) sharing resources among pupils was observed, and (4) positive interdependent learning context was developed.

Thompson (2016) had a mixed method study in which he formed two groups of learners - one using multimodal tangrams while the other using concrete and virtual tangram manipulatives. Those using multimodal tangrams had significant higher mathematical achievement than those using concrete and virtual tangrams. But what is interesting in his study is that, whatever the mode of using tangram is, it was observe and concluded that the use of tangram became the medium for learners to experience three things - (1) having experiential knowledge of composition and decomposition of shapes, (2) deep understanding of shape congruence, and (3) visualization of transformations.

Liu (2014) experimented on using tangram as an outdoor activity and its benefit on performance. The writer called the game Tangram Race. It's an outdoor physical game designed for elementary school students. The researcher found out that through outdoor game using tangram, academic performance can be enhanced to a certain extent.

The benefits of tangram is not only studied and observed in academic performance and attitude towards learning. Saleem, Anderson and Barlett (2015) have found its significance in psychology. In doing Tangram Tasks, helpful and hurtful experience is expressed or revealed. Also, the choice of what pattern to 
solve shows the emotional status and conflict of a person.

All of the above readings could contribute to the present study in such a way that they give light to what was already known about the use and benefit of tangram to learners' performance, behavior, and attitude towards learning. The concepts already been established through studies and write-ups can support or contradict whatever findings may arise as a result of this investigation.

\section{Research Design and Methodology}

This part of the study lays down the research approach used to attain the objectives in mind at the beginning of the study. This also highlights the subjects or respondents, the data gathering technique, the data gathering procedure, the instrument, the ethical consideration, and the manner of data analysis.

\subsection{Research Design}

Qualitative design in doing a research study was used in exploring the topic for this paper. Creswell (2003) provides three characteristics for a qualitative research: (1) makes knowledge claims based on constructivist perspectives, (2) uses strategies of inquiry, and (3) collects open-ended emerging data with the primary aim of developing themes from the data. In doing this research, these three characteristics were met. The constructivist perspective of putting together the ideas of the subjects or respondents were done. It's a good note that the ideas or data were collected from the seven subjects who were in secondary, tertiary and college graduate levels. To gather data, the researcher made use of qualitative inquiry in which the questions were given every after the one-hour-and-forty-minute challenge of solving eight to nine tangram puzzles. After collecting answers from open-ended questions, the researcher developed themes that give solution to the problems posted at the beginning of the study.

\subsection{The Subjects/Respondents/Players}

The subjects, respondents and players are one and the same in this study. The number of subjects who played the tangram was dependent on the acceptance of the challenge forwarded in social media. There were seven who responded positively. It is interesting to note that the number of subjects were also the number of pieces in a tangram. Under the qualitative research design, the number of respondents is not strict in the sense that as long as the saturation point of data needed and the pattern of answers were already established, the number of respondents is considered sufficient. And so, this study proceeded with this number of respondents.

\subsection{Data Gathering Technique}

To obtain data needed to answer the six specific questions stated in the Statement of the Problem, the researcher solicited the question to the players every after day of challenge. There were seven days of challenge wherein the first day was allotted for orientation, and for the remaining six days, one question each day was given. Players need to give the answer within the day, through social media, and in at least six complete and comprehensive sentences so that the researcher could analyze their answers with the aid of word count. The word count helped in developing themes through analysis of the answer and explanation of the players.

\subsection{Data Analysis}


To analyze and process the respondents of players leading to the development of themes, a table and a figure were needed to be developed - the table of word counts and the 2-D word cloud of most frequently appearing words in the responses. Each of the questions in SOP had corresponding word count and 2-D word cloud. To maximize the use of figures developed from tangram pieces and to make the presentation interesting, tangram patterns were utilized in 2-D word clouds - kangaroo, flower, chimney house, direction arrow, eagle, and ballerina.

\section{Presentation, Interpretation and Analysis of Data}

This part of the study focuses on the presentation of the word count and word cloud of the responses, interpretation, and internal and external analyses of the themes developed.

\subsection{Considerations in Solving Tangram Puzzles}

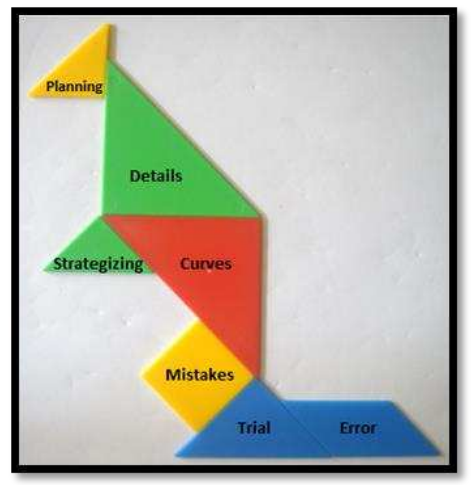

Fig 1. Word Cloud on Things to Consider in Playing Tangram

The figure in the previous page summarizes the responses of players to SOP \# 1 which was the things to consider in solving tangram puzzles.

Based from the word cloud of the responses on things to consider in playing tangram, three themes were developed.

- Looking into details - A player may have presumptions that he already knows the figure so he may rush into putting together the pieces of tangram and forming the figure he has in mind. And when he is already done, the figure that he has formed might be different with the one is presented, so he has to redo it. This is where looking into the details play an important role. Every turn or curve needs to be followed. Looking into the details does not only mean looking at the figure that needs to be replicated, but looking into the pieces of tangram on where it would fit in the part of the figure. Those details, either small or big, would be the start of figuring out what would be the next piece to fit in.

- Trial and Error - "There is no wrong in trying," they say. Laying down some pieces to have trial and error can also be a consideration in doing tangram puzzles. When some pieces are laid down, some wrong notions about the parts of the pattern can be eliminated, reducing the possibilities to slim choices, thus, getting near the correct arrangement of pieces to solve the puzzle.

- Planning - Some would consider planning as negligible in solving tangram puzzles. But when we look at the details and try to one-by-one think of the pieces on where it should be placed on the figure, it is already considered part of planning. In solving tangram puzzles, planning is tantamount to strategizing. When some portions of the figure suggest fitting of one of the pieces of the tangram, it reduces the number of pieces that need to be used until all pieces are put in place. 


\subsection{Best Way to Solve Tangram Puzzles}

The figure that follows summarizes the responses of players to SOP \# 2 which was deals with the best way to solve tangram puzzles.

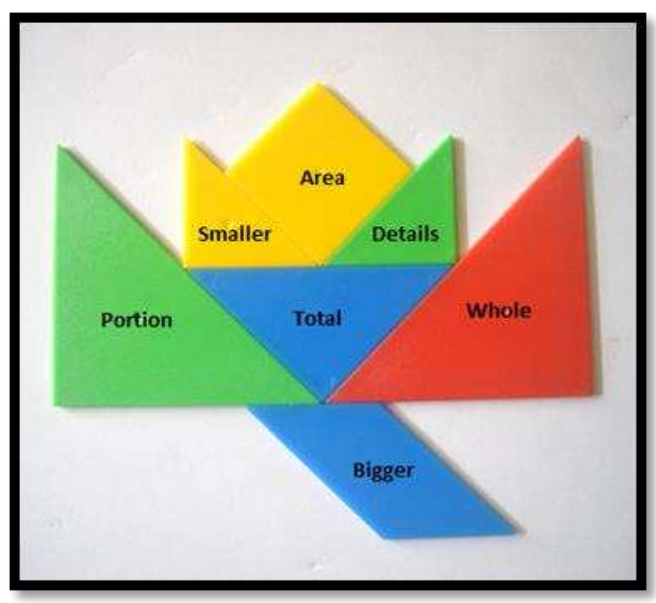

Fig. 2. Word Cloud on Best Way to Solve Tangram Puzzles

Based from word cloud of the responses on best way to solve tangram puzzles, three themes were developed.

- Focusing on the whole portion - Every pieces of tangram complement each other. When we just focus on big or small portions, confusion may arise as to how the remaining pieces part into the whole figure. Tangram contains seven pieces of three kinds - triangle, parallelogram and square. When the whole portion of the figure that needs to be solved is put into mind, the manner on how the seven pieces would complement each other is put into consideration.

- Focusing on bigger portions - If looking into the whole picture falls short of the solution to a tangram puzzle, looking at the bigger portion may help. The big portion consumes a lot of space, therefore if the proper pieces were used on that space, the bigger portion, too, of the puzzle is already solved. Focusing on the big portion gives advantage on solving the tangram fast. It also lessens the time of fitting the remaining pieces on the smaller portion of the figure.

- Focusing on smaller portions - Though this strategy helps, this is the least among the three. Focusing on smaller portions is easy because it's the minute detail of the picture and so, the smaller pieces of tangram would be needed to fill it up. When the smaller pieces of tangram are already used, the bigger portions would now be easy to use. The problem only happens when the smaller pieces are already used, the remaining big pieces of the tangram would have limited place in the pattern to be solved, thereby causing problem on finishing the task.

\subsection{The Use of Imagination in Solving Tangram Puzzles}

The figure that follows summarizes the responses of players to SOP \# 3 which was the role of imagination in solving tangram puzzles 


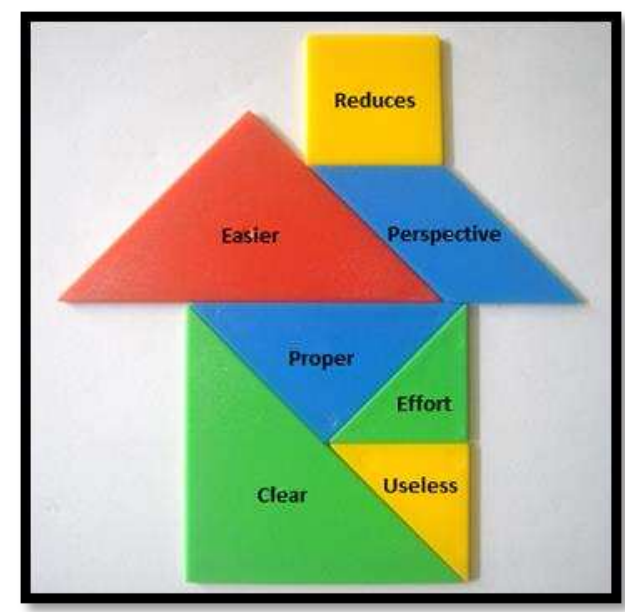

Fig. 3. Word Cloud Use of Imagination in Playing Tangram

Based from the word cloud of the responses on the use of imagination in playing tangram, three themes were developed.

- It makes things clear and the solution easier to obtain. - Imagining things would put us into a different world where we can focus. It is the same in playing tangram. Imagining how the combination of pieces form the needed pattern, the figure becomes clear and the solution easier to obtain. Even without the moving of literal pieces, the mind can move those pieces, thereby making the solution already done even when the hands are not yet moving the pieces of tangram. Imagining the pieces of tangram like imagining the personalities in the story that we are reading helps us move the pieces in our mind, thereby solving the puzzle easier and faster.

- It put things into proper place and perspective. - Of course, the power of imagination in solving tangram puzzles won't work if a person is not yet acquainted with the seven pieces constituting a tangram. Through imagination, a player can fit one or more pieces or even all pieces into their proper place. If there are times that not all pieces are already put in place, imagination can help a person reason out on different perspectives where those pieces already used can be transferred to other place so the remaining ones can fit, too.

- It reduces useless effort. - A beginner may resort into trial and error which would waste time and effort. Once acquainted with the pieces and have seen some basic combinations, time and effort are reduced using imagination. Instead of trial and error, a player would imagine first if his idea would solve the pattern or not.

\subsection{Enhancement of Logical, Analytical \& Critical Thinking through Tangram}

The figure that follows summarizes the responses of players to SOP \# 4 which was the logical/analytical/critical thinking in playing tangram. 


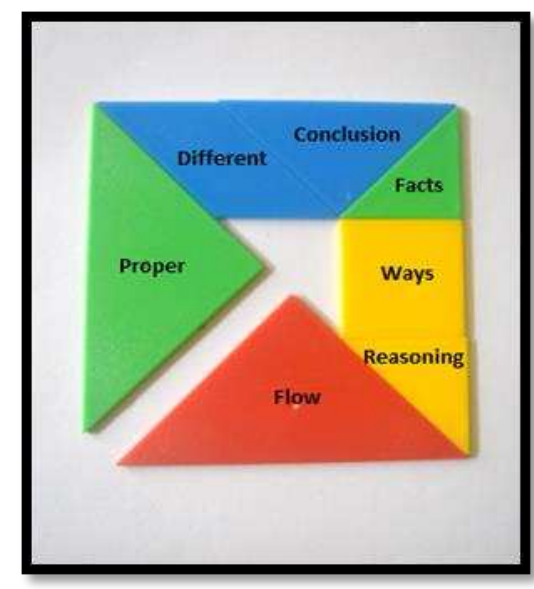

Fig. 4. Word Cloud on Enhancement of Logical/Analytical/Critical Thinking

Based from the word cloud of the responses on the enhancement of logical, analytical and critical thinking, three themes were developed.

- Proper flow of thought in the process of making decisions or conclusions is exercised. - Solving tangram puzzle would not be possible if a person insist on a shape that is near the goal but not exactly like it. Playing tangram trains a person to have sound judgments and decisions proceeding from right logic. The knowledge on why and how things happen provides a person a venue to be sound and logical in his thinking, and tangram can help on this aspect.

- Deep thinking in considering different ways and solutions is given importance. - In playing tangram, all possible ways to solve the puzzle need to be considered. Life has many solutions but it is almost always that there is a best solution to every problem. Tangram trains a person to consider pros and cons, weighing the advantages and disadvantages, and with those data, decide for the best solution.

- Correct reasoning based from facts or evidence is practiced. - Scientific attitude teaches us that we have to decide based on facts and not feelings. Playing tangram teaches the same. The facts are the pieces of tangram. The evidences are the pattern that we need to solve. The facts and evidence are already available. We just to have the correct arrangement of facts in order for the evidence to truly shine. When a player looks at the details, turns and curves of the figure, he learners to have correct reasoning why such piece of a tangram would be the correct one that will fit into it, and not the other one.

\subsection{Developing Numeracy Skills through Tangram}

The figure that follows summarizes the responses of players to SOP \# 5 which was the development of numeracy skills through Tangram. 


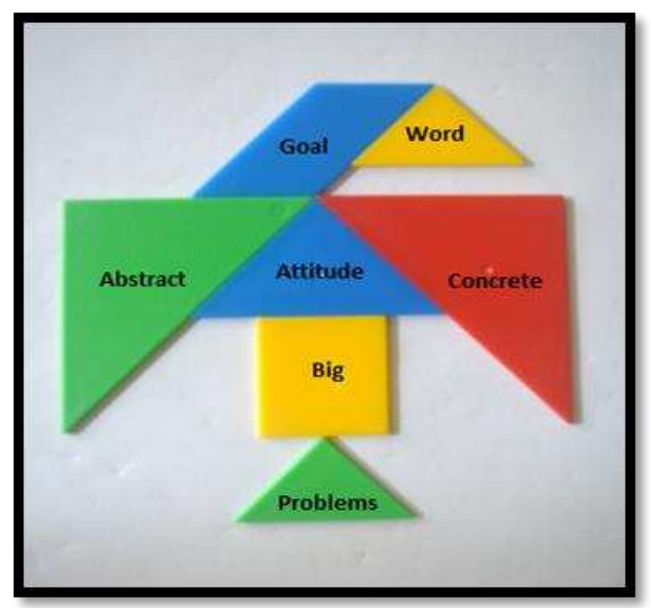

Fig. 5. Word Cloud on Development of Numeracy Skill Thru Tangram

Based from the word cloud of the responses on development and enhancement of numeracy skills to consider in playing tangram, four themes were formed.

- Tangram can train the mind in dealing with abstracts and apply them in concrete things. - While the patterns that need to be solved are abstract, they turn out to be concrete when players move the pieces so as to replicate the figure. One numeracy skill is having the ability to associate abstract with concrete, or vice versa. And tangram aids in doing that.

- Tangram can assist in molding right attitude towards achieving goals and success, thereby improving skills like numeracy. - There is a fulfilment when a player solves a puzzle, and the fulfilment is something that comes out of a proper attitude towards success. If a person learns that in tangram, then he can apply that attitude to gain heights in numeracy skills like arithmetic, comparing, problem solving, proving theorems, interpreting results, analyzing and sorting.

- Tangram can aid learners in looking at the big picture without taking for granted the small details. Dealing with shapes is one numeracy skill, and tangram indeed has a lesson for players and enthusiast. A person cannot just look into the bigger picture and neglect the small details, otherwise he will go wrong.

- Tangram can enhance skill in solving word problems. - Solve word problem is a numeracy skill that can be enhanced through constant playing of tangram. A person learns to consider first the details before taking any action, and this is the same first step in solving problems.

\subsection{Characters Formed in Playing Tangram}

The figure that follows summarizes the responses of players to SOP \# 6 which was characters formed in playing tangram. 


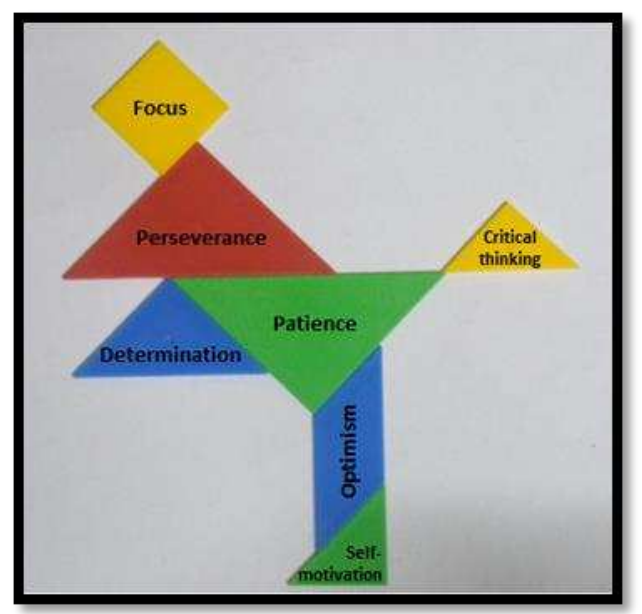

Fig. 6. Word Cloud on Characters Formed in Playing Tangram

Based from the word count and word cloud of the responses on characters formed in playing tangram, things to consider in playing tangram, seven answers were prevalent.

- Patience - Solving patterns in tangram requires time. There is no shortcut into it. Patience is a virtue that helps a player solves puzzles.

- Perseverance - If patience says wait till the right solution comes, perseverance says keep up the energy while waiting. This means not giving up on strength and this can be applied in real life.

- Determination - If perseverance helps a person not to lose strength, determination keeps him attuned to his goal. This makes him not quit easily because he is determined to step on the finish line.

- Focus - This keeps a person to have single mind in reaching for his goals. Nothing can distract a person who is focused, even difficulties or adverse situations. Tangram helps in having this developed in a person

- Optimism - However difficult are some patterns, players were able to solve it through positive thinking that they can solve it as others did. An optimistic person will say that he can overcome whatever happens.

- Critical thinking - Analysis of facts, evidence and various possibilities are present in playing tangram. When an person is accustomed to weighing things before proceeding with any action, they his critical thinking is being used and it keeps him at the right track.

- Self-motivation - Playing tangram teaches a person to try it again if ever he fails, to stand and motivate oneself because it is his responsibility to make himself grow with the life God has given to him. If others would not, then he should motivate himself to carry on.

The findings in this study supports the findings of previous studied done in the exploring the benefits of playing tangram. Though tangram is associated with Geometry because of shapes, area, size and shape, it is established here that playing tangram aids in enhancing numeracy skill both directly and indirectly. Such skill like sorting, comparing, contrasting, analyzing and reasoning is some of direct numeracy associations of playing tangrams. Indirectly, other numeracy skills are also being enhanced like problem solving, proving and simulating. As Tchoshanov (n.d.) exposed that the idea of tangram having relation to Number Sense, Algebra and Measurement, so this study connects tangram to enhancement of numeracy skills. If Stöcker-Segre (2015) displayed the significance of tangram concepts to binary numbers and fractal dimensions, this study also proves how tangram trains a player in having enhanced logical, analytical and critical thinking which are needed in the study of different branches of Mathematics. Problem solving, as one numeracy skill that tangram can aid in enhancing were both seen the present study and in the study made by Khairiree (2005). 
The desirable attitudes that Bahadur K.C. (2017), Lin, Shao and Niramitranon (2011) found out in their studies that involves tangram was also shown in the result of this study in such a way that players pinpointed the characters that can be developed in playing tangram. This classic puzzle indeed has many benefits and this should be considered as solution to problems involving numeracy skills both in public and private teaching institutions.

\section{Conclusion and Recommendation}

This part of the study showcases the conclusion that deals with the main issue and the recommendation to targeted persons, and the author's reflection.

\subsection{Conclusion}

Analyzing the responses of the tangram players produces the following themes which serve also as answer to the major issue of this study:

Numeracy skills are being enhanced in playing tangram due to the following reasons: (a) Tangram can train the mind in dealing with abstracts and apply them in concrete things, (b) Tangram can assist in molding right attitude towards achieving goals and success, thereby improving skills like numeracy, (c) Tangram can aid learners in looking at the big picture without taking for granted the small details, and (d) Tangram can enhance skill in solving word problems.

\subsection{Recommendation}

Based from the findings and conclusion that resulted from conduct of this study, the following recommendations are now laid down here:

- Learners are encouraged to play tangram either in school on vacant time or at home to practice deep thinking and enhance numeracy skills. There are more than 300 patterns available online that would surely raise interest both for beginners and advanced.

- Math teachers should include solving tangram either as daily routine or as part of motivation to connection topics. Geometry is not the only subject in which playing tangram can be utilized but to all branches of Mathematics, both for elementary and secondary education.

- School heads should promote the use of tangram and be able to initiate avenues in which the benefit of playing tangram can be discussed. The school head should also spearhead or at least support Math Department projects that highlight the use of tangram like in Math Camp, Math Fest, or any other school events in which tangram tournaments can be one of the highlights.

- Curriculum developers both in basic and tertiary education should maximize the use of the concept of tangram in developing lessons not just in Geometry but also in Algebra, Trigonometry, Analytic Geometry, Calculus and Number Theory. For higher learning, research and investigation can be a challenging project or group assignment.

- The community can assist in developing tangram pieces made of different materials like wood, colored Styrofoam, thick cardboard, or other indigenous materials that would promote communities product or culture. Barangay officials who are under academic board can communicate with the school heads or math teachers with regards to this need for learners' use.

- Future researchers can investigate on the benefits of playing tangram to other discipline like Science, Language, Sociology and Economics. While it has been known to be of help in Psychology as mentioned in the work of Saleem, Anderson and Barlett (2015) in the Chapter 2 of this paper, it is possible that playing 
tangram also caters assistance on those field of study mentioned.

\section{Acknowledgment}

The author would like to acknowledge the seven learners who accepted the challenge of online tangram tournament, who also patiently answerred open-ended questions given to them as part of the development of this study. Though there were difficulties of data load in some remote areas, these tangram players conscientiously made themselves present on scheduled time of play and with persistence attitude, played and solved patterns to the best of their ability. They did not quit the challenge though there were times the pattern was a bit difficult. They are, indeed, CERTIFIED TANGRAM COMPLETERS!

\section{References}

Bahadur K.C., Bishnu. (2017). Effectiveness of tangram in teaching concept of Geometry at basic level. [For the partial fulfillment of requirement for the degree of Master of Education]. Department of Mathematics Education, Central Department of Education, Tribhuyan University. Kirtipur, Kathmandu, Nepal.

Creswell, J.W. (2003). Research design: qualitative, quantitative, and mixed approaches ( $2^{\text {nd }}$ ed.). Thousand Oaks, CA: Sage.

Department of Education. (2018). Results-based performance management system-Philippine professional standard for teachers (RPMS-PPST), module 4. Quezon City, Philippines.

Khairiree, K. (2015). Creative thinking in Mathematics with tangrams and the geometer's sketchpad. Proceedings of the 20 ${ }^{\text {th }}$ Asian Technology Conference in Mathematics. Leshan, China.

Lin, C., Yin-juan S., Jitti, N. (2011). The impact of using synchronous collaborative virtual tangram in children's geometric. Computer Science.

Liu, Y. (2014). Tangram race mathematical game: Combining wearable technology and traditional games for enhancing Mathematics learning. [Submitted to the faculty of the Worcester Polytechnic Institute in partial fulfillment of the requirement for the Degree of Master of Science in Interactive Media and Game Development].

Saleem, M, Anderson, C. A., and Barlett, C. P. (2015). Assessing helping and hurting behaviors through the tangram help/hurt task. Personality and Social Psychology Bulletin. Vol. 41(10) 1345 - 1362. Society for Personality and Social Psychology, Inc.

Slocum, J. (n.d.). Tangram: the world's first puzzle craze. Published by Sterling

StÖcker-Segre, S. (June 2015). Tangram, teaching and technology. Conference Paper. Davidson Institute of Science Education and Achva Academic College

Tchoshanov, M. (n.d.) Building students' mathematical proficiency: connecting mathematical ideas using the tangram. Learning and T eaching Mathematics, Vol. 10, pp. 16-23. University of Texas, El Paso.

Thompson, T. (2016). The effects of concrete, Virtual, and multimodal tangram manipulatives on second grade elementary students Mathematics achievement and development of spatial sense: a convergent parallel mixed methods study.[ Submitted to the Faculty of the Graduate College of Oklahoma State University in partial fulfillment of the requirements for the Degree of Doctor of Philosophy].

Tian, X. (2012). The art and Mathematics of tangrams. Bridges 2012: Mathematics, Music, Art, Architecture, Culture. Teachers College, Columbia University, New York, USA.

Wikipedia. (2020). Tangram. 